University of Nebraska - Lincoln

DigitalCommons@University of Nebraska - Lincoln

Entomology Papers from Other Sources

Entomology Collections, Miscellaneous

1998

Impact of Temperature and Humidity on Host-Pathogen

Interactions Between Beauveria bassiana and a Coccinellid

R. R. James

ManTech Environmental Technologies, 200 SW 35th Street, Corvallis, OR 97333

B. A. Croft

Department of Entomology, Oregon State University, Corvallis, OR 97331

B. T. Shaffer

ManTech Environmental Technologies, 200 SW 35th Street, Corvallis, OR 97333

B. Lighthart

U. S. EPA Western Ecological Division. National Health and Environmental Effects Research Laboratory, 200 SW 35th Street, Corvallis, OR 97333

Follow this and additional works at: https://digitalcommons.unl.edu/entomologyother

Part of the Entomology Commons

James, R. R.; Croft, B. A.; Shaffer, B. T.; and Lighthart, B., "Impact of Temperature and Humidity on HostPathogen Interactions Between Beauveria bassiana and a Coccinellid" (1998). Entomology Papers from Other Sources. 85.

https://digitalcommons.unl.edu/entomologyother/85

This Article is brought to you for free and open access by the Entomology Collections, Miscellaneous at DigitalCommons@University of Nebraska - Lincoln. It has been accepted for inclusion in Entomology Papers from Other Sources by an authorized administrator of DigitalCommons@University of Nebraska - Lincoln. 


\title{
Impact of Temperature and Humidity on Host-Pathogen Interactions Between Beauveria bassiana and a Coccinellid
}

\author{
R. R. JAMES ${ }^{1,2}$ B. A. CROFT,${ }^{3}$ B. T. SHAFFER,${ }^{2,4}$ AND B. LIGHTHART ${ }^{5}$
}

\begin{abstract}
Environ. Entomol. 27(6): 1506-1513 (1998)
ABSTRACT We tested the effect of 2 exposure methods and 2 environmental factors, temperature and humidity, on Beauceria bassiana (Deuteromycotina: Hyphomycetes) mycosis in Hippodamia convergens Guérin-Méneville (Coleoptera: Coccinellidae). We found that the standard EPA bioassay method of exposing nontarget insects by immersion resulted in a per-insect dose that was 5 times greater than that from spray applications. However, this difference did not significantly affect mycosis levels in a simulation of field applications conducted in the greenhouse. In contrast, differences in environmental conditions between the laboratory and greenhouse had a large effect on mycosis. Constant temperatures between 15 and $35^{\circ} \mathrm{C}$ had a significant effect on both germination rate and vegetative growth of $B$. bassiana, with the fastest germination occurring at $25-32^{\circ} \mathrm{C}$ and the fastest growth occurring at $30^{\circ} \mathrm{C}$. Although temperature affected the rate of conidial germination, total germination eventually reached $97-100 \%$ at all temperatures. Contrary to these results, levels of mycosis in lady beetles decreased as temperatures increased over this same range. Although high levels of humidity are required for conidial germination, we found no well-defined threshold period of high humidity exposure required for mycosis in this insect. In other words, the effects of temperature and humidity on free-living stages of the pathogen are not sufficient to explain the effect of these factors on mycosis. We suggest that temperature and humidity also affect physiological interactions between the host and pathogen.
\end{abstract}

KEY WORDS Beauveria bassiana, Hippodamia convergens, temperature, relative humidity, biological control, microbial pesticides

THE NUMBER OF entomopathogens being registered as biological pest control agents has increased greatly in the past $10 \mathrm{yr}$. These biocontrol agents have low activity toward mammals and birds, leading to the expectation that entomopathogens will have much lower environmental impacts than traditional chemical pesticides. Entomopathogenic fungi, in particular, often are easily propagated and stored, making them attractive as biopesticides. The initial determination of host ranges and infection rates of prospective entomopathogenic fungi are usually conducted in the laboratory. Unfortunately, large discrepancies between field and laboratory results have made it difficult to predict the real effects these fungi have on both target and nontarget insects (Latge et al. 1983, Dorschner et al. 1991, James et al. 1995, Hajek et al. 1996, Inglis et al. 1997).

Several factors may be important in determining why field results differ from laboratory assays, but

\footnotetext{
Current address: USDA-ARS, Subtropical Agricultural Research Center, 2413 E. Highway 83, Weslaco, TX 78596.

${ }^{2}$ ManTech Environmental Technologies, 200 SW 35th Street. Corvallis, OR 97333.

${ }^{3}$ Department of Entomology, Oregon State University, Corvallis, OR 97331.

${ }^{4}$ Current address: Dynamac Corporation, 200 SW 35th Street, Corvallis, OR 97333

${ }^{5}$ U. S. EPA Western Ecological Division, National Health and Environmental Effects Research Laboratory, 200 SW 35th Street, Corvallis, OR 97333.
}

most of these factors can be grouped into 1 of 2 categories-differences in exposures (both in level and form), and differences in environmental conditions. We have previously found Beauveria bassiana (Deuteromycotina: Hyphomycetes) mycosis levels in Hippodamia convergens Guérin-Méneville (Coleoptera: Coccinellidae) to vary greatly in the field after spray applications, but also, field mycosis levels differed significantly from levels found in the laboratory (James and Lighthart 1994, James et al. 1995). Here we set out to determine the degree of effect each of the 2 categories of factors, exposure method and environmental conditions, had in determining field mycosis levels.

It is important to consider that environmental factors and exposure levels are not entirely separate. Environmental conditions, especially temperature and humidity, have long been recognized to play a significant role in the incidence of epizootics of insect pathogens (Benz 1987). For example, Clerk and Madelin (1965) and Daoust and Pereira (1986) demonstrate that temperature and humidity affect both survival and germination rates in $B$. bassiana. If temperature affects germination percentage in conidia, then it also affects the concentration of infective units in the field. Also, B. bassiana conidia have been shown to require humidity levels $\geq 92 \%$ RH for germination (Walstad et al. 1970). We expect the effect of humidity to be greatest during the initiation of infection be- 
cause it is primarily a requirement for conidial germination.

To compare these factors, 3 hypotheses were tested: (1) that differences in application methods between standard laboratory assays and spray applications are sufficient to cause observed differences in mortality; (2) that increases in temperature (within the range of growth for both the pathogen and the insect) increase the proportion of conidia that germinate (effectively increasing the concentration of infective units), and correspondingly, the proportion of insects killed by mycosis; and (3) that a critical period of exposure to high ambient humidity $(\geq 96 \%)$ is required for infection to occur in $H$. convergens.

\section{Materials and Methods}

Culture of Organisms. Neonates of $H$. convergens were used in all experiments, and were obtained from in-house laboratory colonies which had been in culture for $6 \mathrm{yr}$; however, new wild adult beetles were added to the colony approximately every 6 mo. Mated adult females were maintained on live pea aphids, Acyrthosiphon pisum (Harris) (Homoptera: Aphididae). Eggs were collected daily, washed with $0.2 \%$ hyperchlorite solution, and stored at $12^{\circ} \mathrm{C}$ for up to 1 week. Prior to an experiment, eggs were placed at $25^{\circ} \mathrm{C}$ for $3 \mathrm{~d}$ to hatch. One day prior to experimental treatments, neonates $(0-24 \mathrm{~h}$ after eclosion) were placed individually in sterile 20 -ml glass scintillation vials and fed live pea aphids. Larvae were fed fresh aphids every 24-48 h (as needed) in all experiments. Scintillation vials were closed with foam test tube stoppers to allow for air flow into the vial. For more detailed insect rearing instructions for $H$. convergens and $A$. pisum, see James and Lighthart (1992).

Beauveria bassiana (ARSEF 2883) was obtained from the U.S. Department of Agriculture's Collection of Entomopathogenic Fungal Cultures, Ithaca, NY, and cultured on Sabouraud Maltose Agar (Difco Laboratories, Detroit, MI) with yeast extract (SMAY) at $25^{\circ} \mathrm{C}$. For all assays, conidia were scraped off the surface of agar plates that were 14-21 d old, suspended in sterile deionized water using a hand-operated tissue grinder, and stored overnight at $7^{\circ} \mathrm{C}$. The tissue grinder produced a uniform suspension of conidia, which are hydrophobic, without having to use a surfactant. The concentration on the initial mixture was estimated using a hemocytometer, and dilutions were made based on this estimate. The concentration of viable conidia (colony-forming units, cfu's) was determined using standard plate count technique on SMAY. Unless otherwise indicated, cultures from all tests were subcultured twice from B. bassiana-infected $H$. convergens larvae.

In some of the experiments described below, we needed a selective agar medium to quantify fungal spore densities after application. Without at least a semiselective agar, contamination from environmental bacteria and yeast can preclude our ability to enumerate B. bassiana colonies. The selective agar chose consisted of 2 antibacterial agents-crystal violet $\left(10 \mu \mathrm{g} \mathrm{ml}^{-1}\right)$ and chloramphenicol $\left(230 \mu \mathrm{m} \mathrm{m}^{-1}\right)-$ and 2 fungicides - benamyl $\left(75 \mu \mathrm{g} \mathrm{ml} \mathrm{m}^{-1}\right)$ and dodine $\left(280 \mu \mathrm{g} \mathrm{ml}^{-1}\right)$ in SMAY (Sneh 1991, James et al. 1995). To determine whether the selective medium reduced the number of colonies formed (thereby biasing enumeration), we spread plate $0.1 \mathrm{ml}$ of a single preparation of $B$. bassiana spores suspended in $0.01 \%$ Tween 80 on 3 plates of the selective agar, and on 3 plates of SMAY agar. Spores used in the innoculum were collected from plates of strain 2883 that were 2 generations from cultures received by U.S. Department of Agriculture's Collection of Entomopathogenic Fungal Cultures. We then allowed sufficient time for colonies to develop (3-5 d) and compared colony counts between the 2 types of media.

Comparison of Laboratory Assays with Spray Applications. Two different methods of exposing beetles to $B$. bassiana and 2 different environmental conditions of incubation after exposure, were tested to determine which of these 2 factors best explained differences in insect mortality seen between field and laboratory experiments. The experiment consisted of 3 treatment groups. In the 1st group, insects were treated and incubated as described in the EPA laboratory bioassay protocol used to assess the pathogenicity of fungal agents toward coccinellid larvae (James and Lighthart 1992). Neonate beetles were dipped for $10 \mathrm{~s}$ in a mixture of B. bassiana conidia in water, incubated at $25^{\circ} \mathrm{C}, 96 \% \mathrm{RH}$ for $72 \mathrm{~h}$, and thereafter at $25^{\circ} \mathrm{C}, 70 \% \mathrm{RH}$ with a photoperiod of $14: 10$ (L:D) h. Control larvae were treated similarly except sterile water was used instead of the $B$. bassiana mixture. In the 2nd group, larvae were exposed to $B$. bassiana in the laboratory as just described, then placed in cages in greenhouse alfalfa plots. Control and B. bassiana-treated larvae were placed in separate plots. For the 3rd treatment, uncaged larvae were placed in plots and sprayed with either water or the same $B$. bassiana mixture used to treat larvae in the laboratory bioassay. After the plots were sprayed, larvae were then placed in cages of the same design as those used for the 2nd treatment.

Greenhouse plots consisted of 24 (each 0.6 by $0.6 \mathrm{~m}$ ) plots of 2 -yr-old alfalfa which had been planted directly into the ground in a floorless greenhouse. Plots were arranged in a $6 \times 4$ plot array with $0.6 \mathrm{~m}$ between plots. When laboratory-treated insects were placed in the greenhouse, they were contained individually in tubular nylon-organza cages $(14 \mathrm{~cm}$ wide, $56 \mathrm{~cm}$ long) placed over a single plant stem, $0.6 \mathrm{~g}$ live pea aphid were added as prey, and the cage was sealed with clay. For spray applications, plots were sprayed for $9 \mathrm{~s}$ using a gas-pressurized (20 psi) backpack sprayer. Each time a plot was sprayed with B. bassiana, care was taken to prevent spray drift into other plots by surrounding the plot with a large plastic sheet and walling off the neighboring plots with a 2 nd plastic sheet. After the application, larvae were recovered and caged on alfalfa stems within the sprayed plot using the same nylon-organza cages. Live pea aphid prey $(0.6 \mathrm{~g})$ were added to each of these cages, as well. Insects were recovered at day 8 , mortality was deter- 
mined, and all dead larvae were incubated at room temperature $\left(23^{\circ} \mathrm{C}\right)$ on water agar and observed for production of $B$. bassiana hyphae. Only larvae that produced B. bassiana hyphae were considered to have died from fungal infection (mycosis).

The entire experiment was repeated 3 times. Because conditions varied between experimental runs, a random block design was used, with time of treatment as the replicate block. The concentration of viable conidia in the 1 st, $2 \mathrm{nd}$, and 3 rd replicates were $5 \times 10^{8}$, $2 \times 10^{8}$, and $5 \times 10^{8} \mathrm{cfu} / \mathrm{ml}$ (yielding spray rates of $7 \times$ $10^{14}, 3 \times 10^{14}$ and $\left.7 \times 10^{14} \mathrm{cfu} / \mathrm{ha}\right)$, respectively. These concentrations varied slightly because the actual concentrations of viable conidia were determined at the time of spray and the results were not known before treatments. Thirty-six larvae were used per treatment in the 1st replicate, and 20 insects were used per treatment in the 2 nd and 3 rd replicates. Temperature and relative humidity within the canopy, and within a cage, were recorded hourly during each experiment using a 21X Datalogger (Campbell Scientific, Logan, UT).

In conjunction with a significant $F$ test, a Tukey Studentized HSD test (Proc GLM, SAS Institute 1990) was used to compare means from the 3 treatment groups: (1) insects that were both dipped (to treat with $B$. bassiana) and incubated in the laboratory, (2) insects dipped in the laboratory and placed in greenhouse plots, and (3) those that were sprayed and maintained in greenhouse plots.

To determine the number of conidia that attached to larvae after each treatment, insects were allowed to dry for $2-4 \mathrm{~h}$, and then were homogenized in $0.5 \mathrm{ml}$ $0.1 \%$ Tween 80 in 1.5-ml microcentrifuge tubes using a motorized plastic pellet pestle (Kimble Deltaware, Toledo, $\mathrm{OH})$. Ten insects were used per treatment in the 1 st replicate, and 8 in the 2 nd and 3rd replicates. The number of conidia in this mixture was determined using standard plate count technique on the semiselective medium described above. Plates were incubated at $25^{\circ} \mathrm{C}$ for $5-7 \mathrm{~d}$. An $F$ test was used to determine if the difference between exposure methods resulted in a significant difference in the number of conidia attached to an insect (after log transformation) (Proc GLM, SAS Institute 1990).

Assessing the Effects of Temperature on Conidial Germination Rate. Fresh B. bassiana spores (2 generations from receipt by ARSEF) were spread plate on SMAY in small ( $60 \mathrm{~mm}$ diameter) petri dishes. Conidia were spread at a density sufficient to produce $\sim 100$ $\mathrm{mm}^{-2}$. Thirty-three plates were incubated at each of the following temperatures: $10,15,20,25,30,32$, and $35^{\circ} \mathrm{C}$. At each of the following time periods $-4,6,8,10$, $12,14,16,18,24,48$, and $120 \mathrm{~h}-3$ plates were removed from each incubator, fixed with lactophenol, stained with cotton blue, and the percentage that had germinated was determined microscopically as described by Goettel and Inglis (1997). For each plate, the first 100 spores observed under the microscope were enumerated for germination.

The rate of germination for each temperature was estimated using binary logistic regression analysis
(Proc Logit, SAS Institute 1997). The dependent variable was the number of germinated spores per 100 counted. In the lst step of this analysis, time and temperature were included as independent variables to determine whether temperature had a significant effect on germination rate. In the 2 nd step, a separate logistic model was used for each temperature, and only time was used as the independent variable. This analysis was used to estimate the rate of germination at each temperature.

Assessing the Effects of Temperature on Vegetative Growth of B. bassiana. Fresh B. bassiana spores (2 generations from receipt by ARSEF) were spread plate on SMAY at a density sufficient to produce a lawn of hyphal growth. At $3 \mathrm{~d}$, the agar was cut into 25-mm disks with a sterile No. 2 cork borer. Each disk was placed upside-down onto the center of a $90-\mathrm{mm}$ plate of SMAY and incubated at 1 of the following temperatures: $15,20,25,30,32$, or $35^{\circ} \mathrm{C}$. Ten replicate plates were used for 10 and $25^{\circ} \mathrm{C}$, and 5 replicates were used for all other temperatures.

The bottom of each plate was marked with 2 perpendicular lines that intersected in the center of the fungal disk. Starting on the 3rd day of incubation, the diameter of the fungal disc was measured along each of these lines, and the average was used to estimate radial growth. This measure was repeated every day for 10-d. A linear growth curve was fitted to this data for each temperature using a repeated-measures analysis (Proc Mixed, SAS Institute 1997). In other words, a variance-covariance model was used that incorporated all the measurements that came from a single plate. Because the different levels of the repeated effects represented different days, a time series model was fit for each plate. The intercepts of all the growth curves were found not to be significantly different. This result was expected because all the disks started out the same size. Therefore, the intercepts were not allowed to vary independently in the final model (the only fixed effects used in the model were time and the temperature-by-time interaction). The slope from each model produced in the 2 nd step gave an estimate of growth rate (cm per day) at each temperature. This analysis also gave a $t$-test comparison between the growth rate at $25^{\circ} \mathrm{C}$ and each of the other temperatures.

Effect of Temperature on Mycosis. To assess the effects of temperature on disease development, beetle larvae exposed to $B$. bassiana were incubated over a range of temperatures. Neonates were exposed to the fungus by dipping them in either water (as a control) or a mixture of conidia in water at one of 3 concentrations- $5 \times 10^{6}, 1 \times 10^{7}$, or $5 \times 10^{8} \mathrm{cfu} / \mathrm{ml}$-then were placed individually in the glass rearing vials and incubated at $>95 \% \mathrm{RH}, 14: 10$ (L:D) $\mathrm{h}$, and 1 of the following temperatures: $15,20,25,28$, or $32^{\circ} \mathrm{C}$. After $24 \mathrm{~h}$, the humidity was lowered to $70 \%$, but the treatment temperatures and photoperiod were maintained. Forty insects were used for each temperature and dose. Growth chambers were used to maintain uniform temperatures $\left( \pm 0.5^{\circ} \mathrm{C}\right)$ and were monitored continuously using a hydrothermograph in each 
Table 1. Effect of B. bassiana on $\boldsymbol{H}$. convergens larvae, and level of exposure experienced following different methods of fungal application and incubation

\begin{tabular}{|c|c|c|c|c|c|c|}
\hline \multirow{2}{*}{ Exposure method } & \multirow{2}{*}{$\begin{array}{l}\text { Maintenance } \\
\text { method }\end{array}$} & \multicolumn{4}{|c|}{$\%$ mycosis } & \multirow{2}{*}{$\begin{array}{c}\text { Mean exposure level } \\
\left(\log _{10}[\text { conidia/insect }]\right)(\text { SEM })\end{array}$} \\
\hline & & $\widehat{\text { Repl }}$ & Rep2 & Rep3 & $\overline{\text { Mean }}$ & \\
\hline Laboratory-dipped & Laboratory incubator & 97 & 92 & 95 & $95 \mathrm{a}$ & $4.31(0.04) \mathrm{a}$ \\
\hline Greenhouse spray & Greenhouse alfalfa plots & 36 & 50 & 35 & $40 \mathrm{~b}$ & $3.61(0.10) b$ \\
\hline
\end{tabular}

Proportion of the total larvae that died and produced B. bassiana hyphae when incubated on non-nutritive agar.

Numbers in a column with different letters are significantly different ( $\mathrm{P} \leq 0.05)$ (Tukev studentized HDS).

chamber. Each thermograph was compared daily with a registered thermometer kept in glycerol in the same growth chamber.

Mortality was determined every $24 \mathrm{~h}$ until all insects had either died or pupated, except at $15^{\circ} \mathrm{C}$, which is near the developmental threshold of the convergent lady beetle (Miller 1992). At this temperature, mortality was determined every $24 \mathrm{~h}$ until no further mortality was seen for 3 or more consecutive days in any of the treatments.

An $F$ test was used to determine the effect of temperature on mortality percentage. An arcsine-square root transformation was used to normalize the distribution of means and equalize variance. Abbott's mortality adjustment (Abbott 1925) was used to compensate for the differential control mortality seen at the different temperatures.

The Kaplan-Meir product limit estimate (Proc Lifetest, SAS Institute1990) was used to determine the mean time to death at each temperature for insects exposed to the two highest doses $\left(10^{7}\right.$ and $\left.10^{8} \mathrm{cfu} / \mathrm{ml}\right)$. The lowest dose was not included because an insufficient number of insects died from mycosis at some temperatures. A Wilcoxon test (Lawless 1982;8 Proc Lifetest, SAS Institute 1990) was used to test the global hypothesis that time to death was affected by temperature. The Kaplan-Meir and Wilcoxon tests are nonparametric. This analysis was chosen over an ANOVA of the mean time to death because the same insects were used for each time. Therefore, the data are correlated, making the analysis of variance (ANOVA) inappropriate unless a repeated measures test is used. Furthermore, time to death often does not have a normal frequency distribution, making a nonparametric test more suitable.

Effect of High Humidity on Mycosis. To determine the length of time insects must be exposed to high ambient humidity for B. bassiana infection to occur, 20 neonates were exposed to conidial mixtures as described above at 4 different times. The concentration of viable conidia was $1.7,1.9,1.9$, and $2.0 \times 10^{7}$ for each time, respectively. After exposure, insects were immediately placed at $96 \% \mathrm{RH}$ for each of the following time periods: $0,3,4,8,16$, and $24 \mathrm{hrs}$. Conditions of high humidity ( $96 \% \mathrm{RH})$ were maintained by placing larvae in sealed plastic boxes containing saturated solutions of $\mathrm{KH}_{2} \mathrm{PO}_{4}$ and water. Marcandier and Khachatourians (1987a) recommend that the ratio of container volume to surface area of the salt solution be $\leq 25$. Our containers had a volume of 10.4 liters, and a ratio of 22 (after taking into account the displacement caused by the pan that held the insect vials).

After the initial period of high humidity exposure, beetles were maintained at $70 \% \mathrm{RH}, 25^{\circ} \mathrm{C}$ in a growth chamber. Control insects were untreated and maintained at $70 \% \mathrm{RH}, 25^{\circ} \mathrm{C}$. Dead larvae were incubated at $25^{\circ} \mathrm{C}$ on sterile water-agar and observed for B. bassiana hyphae, and only larvae that produced hyphae were considered to be killed by the fungus.

Linear and quadratic regression analysis was used to determine the effect of high humidity exposure period on mortality percentage (Proc Reg, SAS Institute 1990). The dependent variable was the proportion of larvae dead due to $B$. bassiana mycosis. An arcsinesquare root transformation was used on this variable in order to satisfy the conditions of normally distributed data and homogeneity of variance required by an ANOVA.

\section{Results}

Effect of Selective Agar. The benamyl/dodine selective agar produced $42.7 \pm 2.62$ (mean \pm SEM) colonies per plate, whereas, plain SMAY produced $61.3 \pm 16.33$ colonies. The use of selective agar had no statistically significant effect on colony production. Plate counts were almost identical for all the plates, except 1 in the SMAY treatment that was nearly twice as high as expected.

Laboratory Versus Greenhouse Exposures. H. convergens larvae picked up 3 times more B. bassiana conidia in laboratory exposures than in greenhouse spray applications $(F=5.36, \mathrm{df}=5, P \leq 0.001)$. Although larvae initially had higher levels of exposure to conidia when dipped in the laboratory than in greenhouse spray treatments, the 2 application methods did not lead to significantly different levels of mycosis when the insects were maintained in greenhouse plots (Table 1). On the other hand, when insects were treated in the laboratory and then placed in greenhouse plots, mycosis dropped to less than half that found in the laboratory. This difference was significant $(M S E=102.6, \mathrm{df}=6, P \leq 0.05)$.

In the greenhouse, mean daily high temperatures for the 1st, 2nd, and 3rd replicates were 28, 21, and $23^{\circ} \mathrm{C}$, respectively, and mean daily lows were 16,13 , and $13^{\circ} \mathrm{C}$. The total degree-days (DD) (above $0^{\circ} \mathrm{C}$ ) for each treatment time were 167,134 , and 141 , respectively, compared with 200 DD in the laboratory. The mean daily highs in humidity were 96,98 , and $89 \% \mathrm{RH}$ 


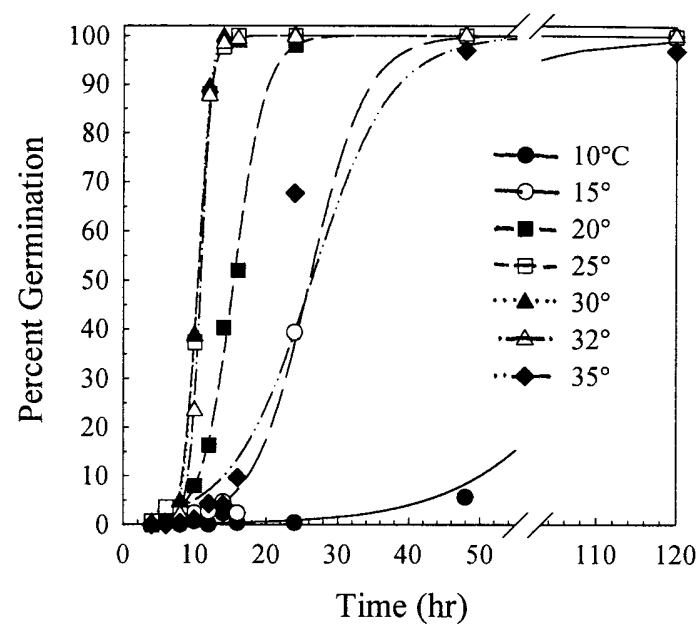

Fig. 1. Effect of temperature on rates of germination of B. bassiana 2883 in vitro.

for the 3 experiments, and the mean daily lows were 73,85 , and $68 \%$, respectively. The greatest differences in humidity were seen in the 1 st $2 \mathrm{~d}$ of the experiments. During this time, $\mathrm{RH}$ levels were between 95 and $75 \%$, 100 and $95 \%$, and 75 and $50 \%$ for the 1st, 2 nd, and 3rd replicate, respectively.

Effect of Temperature on B. bassiana and Mycosis. Temperature was found to have a significant effect on germination rate $\left(\chi^{2}=1792, \mathrm{df}=1, P \leq 0.0001\right)$ (Fig. 1). Spores incubated at 25,30 , and $32^{\circ} \mathrm{C}$ had the fastest rate of germination. The slopes of these logistic lines, respectively, were $1.06,1.21$, and $1.32 \ln (\mathrm{p}) \mathrm{h}^{-1}$, where $\mathrm{p}$ is the proportion germinated. As temperatures decreased below $25^{\circ} \mathrm{C}$, germination took longer, especially at $10^{\circ} \mathrm{C}$ were the slope was only 0.10 . Germination rate also was slower at $35^{\circ} \mathrm{C}$ (slope, 0.17 ). For all temperatures, $100 \%$ germination eventually occurred, except at $35^{\circ} \mathrm{C}$ where it was $97 \%$. For all temperatures, the maximum likelihood estimates for slopes and intercepts of the logit lines were all significantly greater than zero $\left(\chi^{2} \geq 375, \mathrm{df}=1, P \leq 0.0001\right)$.

Temperature also had a significant effect on fungal growth rate (Fig. 2). Maximum growth rate occurred at $30^{\circ} \mathrm{C}$. The rate of growth at $35^{\circ} \mathrm{C}$ and at or below $15^{\circ} \mathrm{C}$ was significant $(t=3.15, \mathrm{df}=353, P=0.002)$, but very slow. All temperatures differed significantly from growth at $25^{\circ} \mathrm{C}\left(t_{10^{\circ}}=12.11, t_{15^{\circ}}=10.60, t_{20^{\circ}}=8.29, t_{30^{\circ}}\right.$ $\left.=3.05, t_{32^{\circ}}=-2.38, t_{35^{\circ}}=10.30 ; \mathrm{df}=353, P \leq 0.02\right)$.

Temperature had a significant effect on insect mortality after exposure to B. bassiana conidia $(F=17.18$, $P \leq 0.001$ ). Unlike the effect of temperature on $B$. bassiana germination and growth, mycosis levels appeared to decreased as temperature increased (Fig. 3 ). For control insects, mortality was lowest at 20 $28^{\circ} \mathrm{C}$ and increased at temperatures above and below that (Fig. 3), indicating that both the high and low temperatures tested were stressful for the insects.

Based on the survival distribution function, temperature had a significant effect on the proportion of insects surviving over time at the medium and high

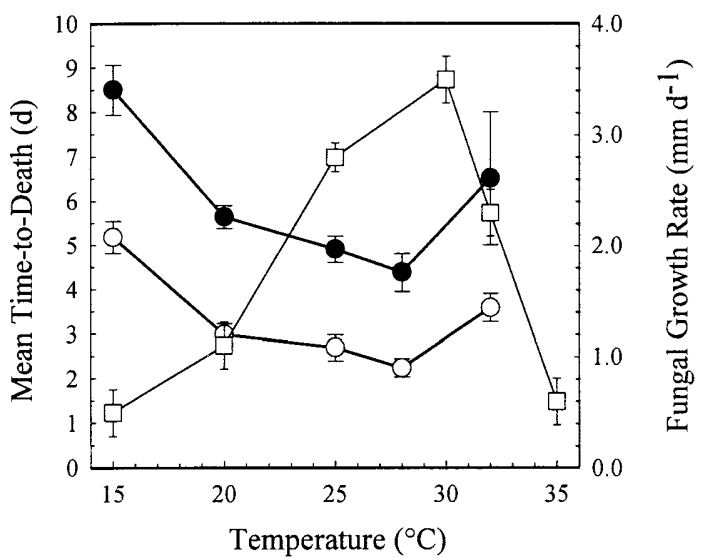

Fig. 2. Effect of temperature on vegetative growth rate of $B$. bassiana in vitro ( $\square$ ) and on the rate of death of H.convergens when exposed to the pathogen at the 2 different rates of $1 \times 10^{7}(\mathbf{O})$ and $5 \times 10^{8}(\bigcirc) \mathrm{cfu} / \mathrm{ml}$.

exposure levels $\left(\chi_{\text {med }}^{2}=37.84, \chi_{\text {high }}^{2}=37.8447 .23\right.$; $\mathrm{df}=4, P \leq 0.0001$ ), but temperature did not have a significant effect on time to death in the controls. Mortality occurred most rapidly at moderate temperatures $\left(25-28^{\circ} \mathrm{C}\right)$, a response that was nearly the inverse of the fungal growth pattern (Fig. 2). The effect of temperature on the rate of insect mortality was nearly identical for both the high and moderate exposure rates, except that the magnitude of the effect was different. That is, larvae died more rapidly when exposed to a higher concentration of conidia.

Effect of High Humidity on Mycosis. The period of time that insects were exposed to high humidity $(\geq 96 \% \mathrm{RH})$ had a highly significant $\left(F=14.3, r^{2}=\right.$ $0.36, P \leq 0.0009)(\mathrm{a}=0.014 \pm 0.004, \mathrm{~b}=0.664 \pm 0.158)$

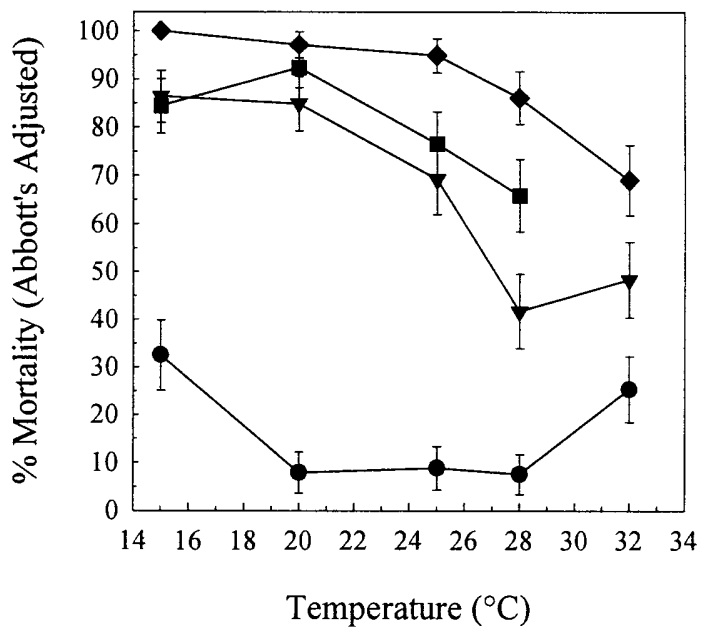

Fig. 3. Effect of temperature on mortality of H.convergens caused by mycosis from $B$. bassiana. Insects were exposed to the pathogen at the 3 different rates of $5 \times 10^{8}(\downarrow)$, $1 \times 10^{7}(\square)$, and $5 \times 10^{6}(\mathbf{\nabla}) \mathrm{cfu} / \mathrm{ml}$; controls $(\mathbf{O})$ were treated with sterile water. 


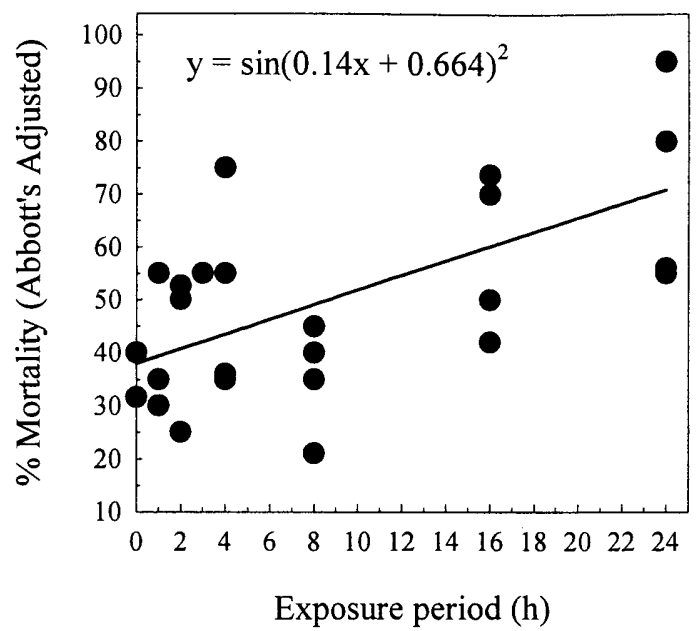

Fig. 4. Levels of mycosis in $H$. convergens larvae following different periods of exposure to high humidity (96\%). Larvae were treated with $\approx 2 \times 10^{7} \mathrm{cfu} / \mathrm{ml}$ of $B$. bassiana, and mortality represents only those insects that produced hyphae after death. Points represent actual mortality rates, and the line was fit by regression analysis.

effect on B. bassiana mycosis (Fig. 4), even though the variability in response was large. The treatment with no exposure to high humidity resulted in a mean mycosis induced mortality of ( $38 \pm 2.1 \%)$, and mortality increased in a nearly linear fashion as exposure time increased (no quadratic line was found that gave a better fit than the linear, arcsine (square root) model). Thus, infections still could occur even without high ambient humidity, and no threshold period of exposure to high humidity was observed.

\section{Discussion}

Most insect pathologists recognize that laboratory bioassays are poor predictors of infection levels that occur in the field. In fact, they can even be poor predictors of which species are susceptible to infection (James et al. 1995, Hajek et al. 1996). We found environmental conditions played a significant role in the results of greenhouse trials, a role that was much greater than the effects of the exposure methods tested.

In our study, the number of conidia that beetles were exposed to when dipped in B. bassiana mixtures in the laboratory was 5 times higher than the initial exposure level from spray applications, but this difference was not sufficient to cause a significant mortality difference in the greenhouse. In addition, mycosis levels in the laboratory were over twice that in the greenhouse, even when insects were exposed in a similar manner. It is true that different field conditions, pesticide formulations, or application methods could lead to much greater differences in exposure levels than we saw, resulting in greater differences in mortality. However, our results demonstrate that even mild differences in environmental conditions can have a great effect on mycosis levels.

The selective agar used in this study probably did not significantly bias spore enumeration. Although the number of colonies formed on selective agar was $\sim 0.7$ times the number formed on nonselective agar, the difference was not statistically significant. Furthermore, because selective agar was used for all the treatments, any such minor effects of the selection agents should not affect the relative differences between them.

The effects of environmental temperature and humidity on mycosis in the host, $H$. convergens, were not the same as on free-living stages of the pathogen, $B$. bassiana. B. bassiana germinated and grew most rapidly at $25-32^{\circ} \mathrm{C}$, yet mycosis in $H$. convergens was greatest at $10-15^{\circ} \mathrm{C}$, where the fungal growth rate was greatly inhibited and conidial germination was greatly delayed. Similar declines in mycosis with increases in temperature have been seen with other entomopathogenic fungi on different hosts (Mohamed and Sikorowski 1977, Gardner 1985, Nnakumusana 1987, Fargues et al. 1997a), but this effect is not universal (e.g., Ferron 1967, Tillotson et al. 1990). For still other entomopathogenic fungi, a threshold temperature occurs above which infection levels suddenly decline to very low levels. This threshold has been found to be at or near $30^{\circ} \mathrm{C}$ for several fungus host pairs (Getzin 1961, Sweeney 1978, McInnis and Zattau 1982, Boucias et al.1984).

The growth rate of this fungal strain is within the range typical for $B$. bassiana, but it appears to be adapted to higher than average temperatures (Fargues et al. 1997b). Peak fungal growth rates occurred at temperatures similar to that for the most rapid death in exposed insects $\left(28-30^{\circ} \mathrm{C}\right)$. At higher and lower temperatures, fungal growth rate was slower, as was time-to-death. In summary, we found mortality to be higher at low temperatures, but rate of disease progression occurred more rapidly at moderate temperatures.

In light of these results, we suggest that temperature may significantly affect this insect's defenses against $B$ bassiana. This result is similar to that found by Inglis et al. (1997), where the incidence of B. bassiana infections was found to decrease when acridids actively increased their body temperature by habitat selection (sunning). However, in the case of the acridids, body temperatures were elevated above the growth threshold for the fungus. With $H$. convergens, we saw a decline in infections even within the optimum temperature range for fungal growth and sporulation (25$32^{\circ} \mathrm{C}$ ).

Insects may be able to resist infection at higher temperatures because of increased metabolism rates or decreased stadium periods leading to more rapid shedding of the cuticle where the fungus attaches and attempts to invade. However, the rate of pathogen germination and growth also is faster at higher temperatures, and would thus compete with such a defense. Another possibility is that insect immunity is affected by temperature. Some metabolic compounds 
induced by heat stress play a role in defense against pathogen invasion. For example, prophenoloxidases are known to be induced by heat stress in arthropods (Ashida and Söderhäll 1984, Leonard et al. 1985), and also to play a role in recognition of foreign proteins in the body (Söderhäll et al. 1994). Thus, heat stress may increase an insect's immune reaction. We speculate that mild heat stress might act to decrease an insect's susceptibility to a particular fungal pathogen, and that this effect may account for some of the differences seen between laboratory assays and field results. On the other hand, cold stress may increase the insect's susceptibility.

The results of the humidity experiment were less clear. We saw a linear, but highly variable, increase in infections as the period of high humidity increased. Although much higher humidity is required for conidial germination, B. bassiana infections have been shown to occur at ambient humidities as low as $50 \%$, probably due to microenvironmental conditions on the insect cuticle (Doberski 1981, Ramoska 1984, Marcandier and Khachatourians 1987b), and our data supports this hypothesis. Perhaps increasing the period of high ambient humidity allowed a larger number of conidia to germinate.

Based on our results, we expect the highest $H$. convergens field mortalities following $B$. bassiana applications to occur at low temperatures $\left(\leq 20^{\circ} \mathrm{C}\right)$ when humidity levels are $>96 \%$ for at least $24 \mathrm{~h}$, or when rainfall provides moisture levels of this magnitude in crop foliage.

\section{Acknowledgments}

We are grateful to Toni Hoyman, Lynn Bucao-Rogers, Deborah Schaller, and Valerie Fieland (ManTech Environmental Technologies, Inc., Corvallis, Oregon), for their help in insect rearing, media preparation, and setting up the greenhouse experiments. We thank L. Ganio, also from ManTech, for advice on statistical analyses. The U.S. Environmental Protection Agency supported this research through contract No. 68-C4-0019 with ManTech Environmental Technology, Inc.

\section{References Cited}

Abbott, W. S. 1925. A method of computing the effectiveness of an insecticide. J. Econ. Entomol. 18: 265-267.

Ashida, M., and K. Söderhäll. 1984. The prophenoloxidase activating system in crayfish. Comp. Biochem. Physiol. B 77: $21-26$.

Benz, G. 1987. Environment, pp. 177-214. In J. R. Fuxa and Y. Tanada [eds.], Epizootiology of insect diseases. Wiley, New York.

Boucias, D. G., D. L. Bradford, and C. S. Barfield. 1984. Susceptibility of the velvetbean caterpillar and soybean looper (Lepidoptera: Noctuidae) to Nomuraea rileyi: effects of pathotype, dosage, temperature, and host age. J. Econ. Entomol. 77: 247-253.

Clerk, G. C., and M. F. Madelin. 1965. The longevity of conidia of three insect-parasitizing hyphomycetes. Trans. Brit. Mycol. Soc. 48: 193-209.

Daoust, R. A., and R. M. Pereira. 1986. Survival of Beauveria bassiana (Deuteromycetes: Moniliales) conidia on ca- davers of cowpea pests stored outdoors and in the laboratory in Brazil. Environ. Entomol. 15: 642-647.

Doberski, J. W. 1981. Comparative laboratory studies on three fungal pathogens of the elm bark beetle Scolytus scolytus: effect of temperature and humidity on infection by Beauveria bassiana, Metarhizium anisopliae, and Paecilomyces farinosus. J. Invertebr. Pathol. 37: 195-200.

Dorschner, K. W., M. G. Feng, and C. R. Baird. 1991. Virulence of an aphid-derived isolate of Beauveria bassiana (Fungi: Hyphomycetes) to the hop aphid, Phorodon humuli (Homoptera: Aphididae). Environ. Entomol. 20: 690-693.

Fargues, J., A. Ouedraogo, M. S. Goettel, and C. Lomer. 1997a. Effects of temperature, humidity and innoculation method on susceptibility of Schistocerca gregaria to Metarhizium flavoviride. Biocontrol Sci. Technol. 7: 345356.

Fargues, J., M. S. Goettel, N. Smits, A. Ouedraogo, and M. Rougier. 1997b. Effect of temperature on vegetative growth of Beauveria bassiana isolates from different origins. Mycologia 89: 383-392.

Ferron, P. 1967. Étude en laboratoire des conditions écologiques favorisant le développement de la mycose a Beauveria tenalla du ver blanc. Entomophaga 12: 257-293.

Gardner, W. A. 1985. Effects of temperature on the susceptibility of Heliothis zea larvae to Nomuraea rileyi. J. Invertebr. Pathol. 46: 348-349.

Getzin, L. W. 1961. Spicaria rileyi (Farlow) Charles, an entomogenous fungus of Trichoplusia ni (Hubner). J. Insect Pathol. 3: 2-10.

Goettel, M. S., and G. D. Inglis. 1997. Fungi: Hyphomycetes, pp. 213-247. In L. A. Lacey [ed.], Manual of techniques in insect pathology. Academic, San Diego.

Hajek, A. E., L. Butler, S.R.A. Walsh, J. C. Silver, F. P. Hain, F. L. Hastings, T. M. Odell, and D. R. Smitley. 1996. Host range of the gypsy moth (Lepidoptera: Lymantriidae) pathogen Entomophaga maimaiga (Zygomycetes: Entomophthorales) in the field versus laboratory. Environ. Entomol. 25: 709-721.

Inglis, D. G., M. S. Goettel, and D. L. Johnson. 1997. Field and laboratory evaluation of two conidial batches of Beuaveria bassiana (Balsamo) Vuillemin against grasshoppers. Can. Entomol. 129: 171-186.

James, R. R., and B. Lighthart. 1992. Protocol for testing the effects of fungal pesticides on nontarget beetles using Hippodamia convergens (Coleoptera: Coccinellidae). Natl. Tech. Infor. Serv. Pub. No. PB92-217-488, U.S. Environmental Protection Agency, Environmental Research Laboratory, Corvallis, OR.

1994. Susceptibility of the convergent lady beetle ( $\mathrm{Co}-$ leoptera: Coccinellidae) to four entomogenous fungi. Environ. Entomol. 23: 190-192.

James, R. R., B. T. Shaffer, B. A. Croft, and B. Lighthart. 1995. A field evaluation of Beauveria bassiana: its persistence and effects on the pea aphid and a non-target coccinellid in alfalfa. Biocontrol Sci. Technol. 5: 425-437.

Latge, J. P., P. Silvie, B. Papierok, G. Remaudiere, C. A. Dedryver, and J. M. Rabasse. 1983. Advantages and disadvantages of Conidiobolus obscurus and of Erynia neoaphidis in the biological control of aphids, pp. 20-32. In R. Cavalloro [ed.], Aphid antagonists. Proceedings of a Meeting of the EC Experts' Group, 23-24 November 1982 , Portici, Italy. Balkema, Rotterdam.

Lawless, J. F. 1992. Statistical models and methods for lifetime data, Wiley, New York.

Leonard, C., K. Söderhäll, and N. A. Ratcliffe. 1985. Studies on prophenoloxidase and protease activity of Blaberus craniifer haemocytes. Insect Biochem. 15: 803-810. 
McInnis, T., and W. C. Zattau. 1982. Experimental infection of mosquito larvae by a species of the aquatic fungus Leptolegnia. J. Invertebr. Pathol. 39: 98-104.

Marcandier, S., and G. G. Khatchatourians. 1987a. Evolution of relative humidity and temperature within a closed chamber used for entomological studies. Can. Entomol. 119: 893-900.

1987b. Susceptibility of the migratory grasshopper Melanoplus sanguinipes (Fab.) (Orthoptera: Acrididae) to Beauveria bassiana (Bals.) Vuillemin (Hyphomycete): influence of relative humidity. Can. Entomol. 119: 901907.

Miller, J. C. 1992. Temperature dependent development of the convergent lady beetle (Coleoptera: Coccinellidae). Environ. Entomol. 21: 197-201.

Mohamed, A.K.A., and P. P. Sikorowski. 1977. Susceptibility of Heliothis zea larvae to Nomuraea rileyi at various temperatures. J. Invertebr. Pathol. 30: 414-417.

Nnakumusana, E. S. 1987. Effects of temperature on the susceptibility of Aedes aegypti (L.) (Diptera: Culicidae) larvae to a mosquito pathogen Coelomomyces stegomyiae in Uganda. Appl. Entomol. Zool. 22: 7-12.

Ramoska, W. A. 1984. The influence of relative humidity on Beauveria bassiana infectivity and replication in the chinch bug, Blissus leucopterus. J. Invertebr. Pathol. 43: 389-394.

SAS Institute. 1990. SAS/STAT user's guide, 4th ed. SAS Institute, Inc., Cary, NC.
1997. SAS/STAT software: changes and enhancements through release 6.12. SAS Institute, Cary, NC.

Sneh, B. 1991. Isolation of Metarhizium anisopliae from insects on an improved selective medium based on wheat germ. J. Invertebr. Pathol. 58: 269-273.

Söderhäll, K., M. W. Johansson, and L. Cerenius. 1994. Pattern recognition in invertebrates: the b-1,3 glucan binding proteins, pp. 97-104. In J. A. Hoffmann, C. A. Janeway and S. Natori, [eds.], Phylogenetic perspectives in immunity: the insect host defense, Landes, Austin, TX.

Sweeney, A. W. 1978. The effects of temperature on the mosquito pathogenic fungus Culicinomyces. Aust. J. Zool. 26: $47-53$.

Tillotson, K. D., D. C. Margolies, and J. R. Nechols. 1990. Effect of temperature and photoperiod on mortality of Melanoplus differentialis (Orthoptera: Acrididae) infected by Entomophaga grylli Pathotype 2 (Entomophthorales: Entomophthoraceae). J. Kans Entomol. Soc. 63: 252-259.

Walstad, J. D., R. F. Anderson, and W. J. Stambaugh. 1970. Effects of environmental conditions on two species of muscardine fungi (Beauveria bassiana and Metarhizium anisopliae). J. Invertebr. Pathol. 16: 221-226.

Received for publication 27 December 1996; accepted 10 June 1998 